\title{
ENSINO DE MATEMÁTICA E EDUCAÇÃO AMBIENTAL: MODELAGEM COM ENERGIAS RENOVÁVEIS NO SEMIÁRIDO BRASILEIRO
}

\author{
Vanessa Danielle Ferreira Lima dos Santos ${ }^{1}$ \\ Hevelyn Kelly Samara Leite de Almeida ${ }^{2}$ \\ Érick Macêdo Carvalho ${ }^{3}$ \\ Tiago Luiz Santana de Souza ${ }^{4}$ \\ Regina Lúcia Félix de Aguiar Lima ${ }^{5}$ \\ Claudemiro de Lima Júnior ${ }^{6}$
}

Resumo: Considerando a forma dissociada que a Educação Ambiental é abordada nas escolas e a dificuldade dos alunos na compreensão de conteúdos de matemática pelo método tradicional de ensino, este artigo apresenta estratégias de ensino da matemática com temáticas de Educação Ambiental. Essa proposta foi desenvolvida a partir da construção e exploração de três atividades didáticas com aplicação de modelagem matemática para avaliação de fontes energéticas sustentáveis para o semiárido. Como resultado, foi possível abordar conteúdos matemáticos e de Educação Ambiental de modo interdisciplinar, contribuindo para a aprendizagem contextualizada da matemática.

Palavras-chave: Energia Eólica; Energia de Biomassa; Interdisciplinaridade.

\footnotetext{
${ }^{1}$ Universidade de Pernambuco. E-mail: vanessa.danielle2008@gmail.com, Link para o Lattes: http://lattes.cnpq.br/2809679348340740

2 Universidade Federal do Vale do São Francisco. E-mail: hevelynkelly23@gmail.com, Link para o Lattes: http://lattes.cnpq.br/8457266898936184

3 Universidade de Pernambuco. E-mail: erick.carvalho@upe.br, Link para o Lattes: http://lattes.cnpq.br/5141503246892602

4 Universidade de Pernambuco. E-mail: tiagosantana.tlss@gmail.com.br, Link para o Lattes: http://lattes.cnpq.br/6121738463687028

5 Universidade de Pernambuco. E-mail: regina.aguiar@upe.br, Link para o Lattes: http://lattes.cnpq.br/8549101690272163

6 Universidade de Pernambuco. E-mail: claudemiro.lima@upe.br, Link para o Lattes: http://lattes.cnpq.br/8114711170508132
} 
Abstract: Considering the dissociated way that Environmental Education is approached in schools and the students' difficulty in understanding Mathematics by the traditional teaching method, this article presents teaching strategies with environmental education mathematics. This proposal was developed from the construction and exploration of three didactic activities with mathematical modeling for the sustainable energetic fonts for the semiarid. As a result, it was possible to approach mathematical content and environmental in an interdisciplinary way, contributing to the contextualization of mathematics learning.

Keywords: Wind Energy; Biomass Energy; Interdisciplinarity.

\section{Introdução}

A modelagem matemática, segundo Bassanezi (2002, p. 16), consiste na "arte de transformar problemas da realidade em problemas matemáticos e resolvê-los, interpretando suas soluções na linguagem do mundo real". É a partir da investigação, da construção e da validação de modelos matemáticos que a modelagem pode ser usada em sala de aula abordando problemas relacionados ao cotidiano dos alunos.

O uso da modelagem matemática permite o estabelecimento de interação entre Energia eólica; Energia de biomassa; Interdisciplinaridade matemática abstrata e prática. Segundo Biembengut e Hein (2005, p.13) "genericamente, pode-se dizer que matemática e realidade são dois conjuntos disjuntos e a modelagem é um meio de fazê-los interagir", o que proporciona experiências com modelos matemáticos a partir de variáveis reais.

De acordo com Biembengut e Hein (2005), ao trabalhar com atividades envolvendo a Modelagem Matemática é possível percorrer as etapas: interação, matematização e modelo matemático. Na etapa de interação, desenvolve-se pesquisa bibliográfica ou de campo para que os alunos conheçam o tema de estudo e identifiquem um problema; na matematização, acontece a transição da linguagem materna para a linguagem matemática do problema; por fim, no modelo matemático, ocorre a construção, a interpretação e validação do modelo do problema.

O modelo matemático é um conjunto de símbolos e relações matemáticas que representam, de alguma forma, o objeto estudado. Pode-se construir modelos matemáticos com características pictóricas ou conceituais. Modelos pictóricos são apresentados por meio de desenho, esquema compartimental ou mapa, enquanto modelos conceituais são constituídos por fórmulas matemáticas ou símbolos. Desse modo, a Matemática torna-se um meio de compreensão e possível modificação da realidade, onde unindo as noções de diversas abordagens da realidade à disciplina, espera-se contribuir para a formação de estudantes independentes, munidos de senso crítico e capazes de refletir e tomar decisões sobre as circunstâncias cotidianas. (BASSANEZI, 2002, p. 17). 
Segundo Bassanezi (2002, p. 24), "a modelagem é eficiente a partir do momento que nos conscientizamos que estamos sempre trabalhando com aproximações da realidade". Dentre as diversas aplicações da modelagem matemática, os temas de Educação Ambiental, apesar de serem de grande relevância para a formação discente, nem sempre são incluídos em sala de aula.

As demandas da sociedade exigem que as práticas em sala de aula abordem situações que despertem a reflexão sobre problemas sociais, econômicos, culturais e ambientais, isso é especialmente importante de ser tratado nos temas transversais como a Educação Ambiental. E uma das alternativas para essa prática é a construção de modelos a partir da modelagem matemática.

A Educação Ambiental na educação básica tem sido frequentemente tratada de maneira dissociada de outras disciplinas, o que acaba por dificultar seu entendimento e associação com a realidade dos alunos (MEDEIROS; RIBEIRO; FERREIRA, 2011). Buscando aliar seus conceitos aos ensinamentos já vistos em sala de aula, emerge então a ideia de sua junção com o ensino da Matemática. Essa junção objetiva contextualizar o ensino matemático, estimulando os alunos a construir hipóteses e solucionar problemas de cunho ambiental tendo a Matemática como base dessas discussões.

Diante desse cenário, foi sancionada, no Brasil, a Lei Federal ํo 9.795 de 1999, que cria a Política Nacional de Educação Ambiental - PNEA, incumbindo o poder público de promover a Educação Ambiental em todos os níveis de ensino. Essa Educação Ambiental vem com o objetivo de construir valores sociais, conhecimentos, habilidades, atitudes e competências voltadas para a conservação do meio ambiente, para que Homem e Natureza se relacionem em sinergia (BRASIL, 1999, p. 1).

Entre as temáticas debatidas na Educação Ambiental, as energias renováveis ocupam lugar de destaque, por terem como matéria prima, recursos inesgotáveis. Esse tipo de energia está aos poucos conquistando o espaço que antes era ocupado totalmente pelas fontes fósseis. Isso, graças ao desenvolvimento tecnológico vigente que permite o aproveitamento dessas fontes renováveis como combustíveis alternativos sem interromper 0 desenvolvimento dos países, promovendo o desenvolvimento sustentável (PACHECO, 2006, p. 5).

Levando em conta a região do Semiárido Brasileiro, há três fontes alternativas de energia renovável com potencial para exploração que se destacam: solar, eólica e biomassa. Isso por conta da crise hídrica, levando em consideração as irregularidades pluviométricas, o que gera uma quantidade de chuva menor do que o índice de evaporação. Sendo o fornecimento de água e de energia um dos fatores físicos mais influentes para os habitantes do semiárido, surgem então tais fontes alternativas para a geração de energia, tendo em vista que há na região com fortes ventos, uma intensa radiação solar e alta produção de biomassa (PACHECO, 2006, p. 6).

Revbea, São Paulo, v.16, № 1: 148-162, 2021. 
A energia eólica, provinda dos ventos, tem hoje uma importante participação na matriz elétrica brasileira, como consequência de políticas específicas para o setor e por ser uma fonte com grande potencial no território brasileiro. Com isso, a energia eólica surge como uma alternativa para minimizar o quadro atual de crise energética decorrente da escassez do recurso hídrico e o crescimento da emissão de gases de efeito estufa pela ampla participação de combustíveis fósseis na matriz elétrica do país (PINTO; MARTINS; PEREIRA, 2017, p. 1084).

A produção de energia a partir de biomassa, também tem ganhado destaque no Brasil, devido a fatores como sua rica biodiversidade, disponibilidade de área para cultivo e condições climáticas adequadas. Resíduos de atividades agrícolas e os rejeitos de suínos, bovinos, aves, ovinos e caprinos são de grande interesse para geração de biogás. O processo de produção do biogás também gera, ao final de cada ciclo, um resíduo com nutrientes minerais que já estão presentes no solo e são utilizados para a sua potencialização. O volume de biogás produzido depende da biomassa utilizada, por algumas possuírem mais matéria biodegradável, bem como do porte do biodigestor, além da temperatura que é submetido (DOS SANTOS; DE NARDI JUNIOR, 2013, p. 84).

\section{Metodologia}

As propostas didáticas foram planejadas para turmas do Ensino Fundamental e/ou Médio sob a mediação do professor. Tais propostas tiveram como tema a utilização da energia eólica e da biomassa, onde foi possível fazer a associação com a Matemática, além de outras disciplinas, como Biologia e Geografia.

\section{Propostas Didáticas}

Foram construídas três propostas didáticas tendo como base a utilização da energia eólica, provinda dos ventos, e a biomassa como solução para o acúmulo de rejeitos urbanos e rurais e o alto custo de energia na atual crise da fonte hidrelétrica, abrangendo conteúdos do Ensino Fundamental e Médio.

Tais propostas se apresentam a partir de uma contextualização, seguida do seu objetivo, construção da situação problema, resolução da mesma e conclusão, por último, os conteúdos matemáticos que estão presentes nos Parâmetros Curriculares Nacionais e o tipo de modelo construído.

\section{Proposta 1: Resíduos Alimentares e o biogás - a energia da biomassa}

De acordo com a Organização das Nações Unidas para a Agricultura e Alimentação, mais da metade da comida produzida no mundo é desperdiçada 
na fase inicial: a colheita. Em média, $46 \%$ do desperdício da comida restante ocorrem no processamento, transporte, armazenamento, comercialização e consumo (FAO, 2013, p. 11-12).

Com isso, o objetivo desse modelo é avaliar, do ponto de vista matemático, a viabilidade da instalação de um biodigestor doméstico em restaurantes como solução para o desperdício de comida, destinando os resíduos orgânicos de maneira proveitosa.

Surge a questão problema: Partindo de um ponto de vista matemático, a instalação de um biodigestor doméstico em um restaurante é uma solução vantajosa para seu desperdício de comida?

Essa proposta pode ser executada a partir do ensino fundamental e aborda os seguintes conteúdos: regra de três simples, noções de volume, proporção e transformação de medidas do sistema internacional.

Tipo de modelo: conceitual e pictórico

\section{Proposta 2: Resíduos da agropecuária e a produção de biofertilizante para a fruticultura}

Segundo dados do Instituto Brasileiro de Geografia e Estatística IBGE, no Censo Agropecuário de 2006, o Brasil possui, em média, 38\% do seu território sendo utilizado na agricultura e pecuária, sendo assim uma das maiores áreas de produção rural do mundo (BRASIL, 2006, p. 100).

Entretanto, o uso indiscriminado dessas terras pode causar danos ao solo e águas superficiais e subterrâneas. Exemplo disso, é o despejo inadequado dos rejeitos gerados a partir da agropecuária, como fezes e urina dos animais. Embora esses rejeitos sejam ricos em matéria orgânica e nutrientes, se eliminados in natura podem contaminar o solo e lençóis freáticos próximos. Essa contaminação pode causar eutrofização dos corpos d'água e morte de organismos aquáticos, contaminação das águas subterrâneas por nitrato e patógenos, ameaçando fontes de abastecimento humano, além de propiciar um excesso de nutrientes e metais pesados nos solos, diminuindo a sua qualidade (SEGANFREDO, 2002, p. 1-2).

Como uma alternativa de solução para essa problemática, surge 0 biodigestor rural. O uso desse equipamento promove um destino mais correto aos rejeitos da agropecuária, alocando os mesmos em um ambiente fechado e impermeável, tornando possível que o processo de decomposição ocorra de forma anaeróbica, resultando em um líquido que pode ser utilizado como adubo orgânico. Dessa forma, tais rejeitos não são despejados in natura, preservando assim o solo e as águas subterrâneas, além de proporcionar uma economia financeira na diminuição ou suspensão da compra de fertilizantes químicos (BARBOSA; LANGER, 2011, p. 88). 
O objetivo desse modelo é descobrir, a partir da matemática, quantas coroas um agricultor pode preencher com biofertilizante produzido por um biodigestor rural em sua capacidade máxima mensal.

Surge, então, a seguinte questão problema: Sabendo que um agricultor planeja adubar seu pomar de mangueiras utilizando a técnica de coroamento, quantas coroas ele consegue preencher com o biofertilizante produzido por um biodigestor rural em sua capacidade máxima?

Essa proposta pode ser executada a partir do 6을 ano do Ensino Fundamental II e aborda conteúdos de Matemática, como noções de formas geométricas, área, volume, transformação de medidas e de biologia como botânica.

Tipo de modelo: conceitual e pictórico

\section{Proposta 3: Força dos ventos e a produção de energia}

A Agência Nacional de Energia Elétrica - ANEEL criou o sistema de bandeiras Tarifárias. Esta é subdividida em três classificações: as bandeiras verde, amarela e vermelha, as quais indicam o valor que custará a energia em função da geração em suas determinadas condições, seja pelos níveis dos reservatórios ou o volume de chuva (ANEEL, 2019, on-line).

Sabe-se que o clima semiárido brasileiro tem por características intensa insolação, altas temperaturas e uma marcante escassez de chuva, com irregulares precipitações de curto período. Esses fatores acarretam insuficientes volumes de água em seus mananciais. Presente no Brasil, predominantemente na Região Semiárida do Nordeste, esse clima abrange os estados do Ceará, Rio Grande do Norte, Paraíba, Pernambuco, Sergipe, Alagoas, Piauí, Bahia e a região sudeste de Minas Gerais (DA SILVA, 2010, p. 19).

Acerca da produção de energia elétrica no país, sabe-se que grande parte desta, provém de usinas hidrelétricas. Com a crise hídrica atual, houve uma redução das afluências naturais dos reservatórios, fazendo com que fosse optado pela geração termelétrica. Essa compra de energia de usinas termelétricas ocasionou uma alta nos valores da energia pagos pelo consumidor final, já que os custos dessa fonte energética são mais altos (GALVAO; BERMANN, 2015, p. 56-57).

Partindo desse aumento constante nas contas de energia do consumidor, a utilização da energia eólica surge como uma alternativa, tanto pela economia financeira, como pela produção de uma energia mais limpa. Além disso, trata-se de uma região com grande potencial para tal, pelos fortes ventos apresentados anualmente de forma contínua (DE OLIVEIRA FEITOSA, 2014, p. 201). 
O objetivo desse modelo é analisar a viabilidade da implantação desse tipo de energia, visto que se trata de um equipamento de alto custo, sendo identificada a economia financeira do consumidor.

A questão problema dessa proposta foi: É rentável para um residente da região semiárida a instalação de um equipamento para produção de energia eólica em sua casa?

Essa proposta pode ser executada com alunos do ensino médio e aborda conteúdos de matemática, média aritmética, velocidade média, regra de três simples e de geografia como cartografia.

Tipo de modelo: Conceitual e Pictórico

\section{Resultados e Discussão}

\section{Resíduos Alimentares e o biogás - a energia da biomassa}

O modelo permite avaliar a viabilidade econômica e ambiental da instalação de um biodigestor doméstico em um restaurante.

Considera-se para avaliação um restaurante numa cidade que vende alimento de acordo com o peso. Foi constatado que o volume de resíduos semanal chegava a cerca de 120 litros, considerando somente os alimentos que sobraram nos pratos dos clientes (dados hipotéticos). Para reaproveitar energeticamente os resíduos, considerou-se a aquisição de equipamentos para produção de biogás, de uma empresa que comercializa biodigestores domésticos e rurais de diferentes capacidades para que seus clientes possam reaproveitar esses resíduos transformados em gás de cozinha substituindo o GLP.

Segundo a empresa de equipamentos para biogás (dados reais - BGS, 2019, on-line), um biodigestor rural de $10 \mathrm{~m}^{3}$ produz mensalmente $150 \mathrm{~m}^{3}$ de biogás a partir de 300 litros de biomassa, necessitando de alimentação diária, o que equivale a 5 botijões de $13 \mathrm{~kg}$ de gás GLP. A empresa dispõe de modelo de biodigestor doméstico de tamanho $3,8 \mathrm{~m}^{3}$, com capacidade máxima de $20 \mathrm{~L}$ de biomassa por dia. Utilizou-se então da regra de três simples para calcular a produção de biogás em $\mathrm{m}^{3}$ por mês e consequentemente a quantidade de GLP no mesmo espaço de tempo (Tabela 1).

Tabela 1: Biomassa, tamanho, quantidade de biogás e gás GLP rural de biodigestor rural e urbano, com incógnitas $\mathrm{X}$ e $\mathrm{Y}$.

\begin{tabular}{cccc}
\hline Biomassa (litro/dia) & Tamanho $\left(\mathbf{m}^{\mathbf{3}}\right)$ & Biogás $\left(\mathbf{m}^{\mathbf{3}}\right)$ & GLP (13kg) \\
\hline 300 & 10 & 150 & 5 \\
\hline 20 & 3,8 & $\mathbf{X}$ & $\mathbf{Y}$ \\
\hline
\end{tabular}

Fonte: Autor 
Para encontrar o valor da incógnita $X$, correspondente a quantidade de biogás em $\mathrm{m}^{3}$, foi realizada a regra de três simples abaixo:

$$
\begin{aligned}
& \frac{10}{3,8} \underset{-\frac{150}{x}}{x} \\
& 10 x=150 * 3,8 \\
& \begin{aligned}
\longrightarrow 10 x & =570 \\
\mathbf{X} & =570 / 10 \\
\mathbf{X} & =57 \mathrm{~m}^{3}
\end{aligned}
\end{aligned}
$$

Feito isso, utilizou-se novamente da regra de três simples para encontrar o valor da incógnita $Y$, correspondente à quantidade de gás GLP em $\mathrm{kg}$, conforme descrito abaixo:

$$
\begin{aligned}
& \frac{150}{57}=\frac{5}{\mathbf{y}} \\
& 150 \mathbf{y}=285 \longrightarrow
\end{aligned} \longrightarrow \begin{aligned}
& \mathbf{y}=285 / 150 \\
& \mathbf{y}=1,9 \mathrm{~kg}
\end{aligned}
$$

Segundo os cálculos, é possível presumir que o restaurante economizaria aproximadamente 2 botijões de gás GLP ao mês, além de destinar seus rejeitos orgânicos em benefício próprio, sendo uma ideia viável.

De acordo com os Parâmetros Curriculares Nacionais - PCN's, têm-se que a regra de três funciona de acordo com as Leis de Proporcionalidade desenvolvendo raciocínio útil para interpretações da realidade, instigando aos discentes ao envolvimento com os aspectos quantitativos e qualitativos (BRASIL, 1998, p. 72).

\section{Resíduos da agropecuária e a produção de biofertilizante para a fruticultura}

A produção de biofertilizante com uso de biodigestor rural para adubação de um pomar de mangueiras (Mangifera indica L.) com oito anos de idade, onde a média do diâmetro de seus caules é de 0,62 metros, o equivalente a um raio de 0,31m a níveis do solo (CARDOSO et al., 2007, p. 210). A fazenda possui um biodigestor rural de $20 \mathrm{~m}^{3}$, que produz $20.000 \mathrm{~L}$ de biofertilizante mensalmente, segundo a BGS Equipamentos para Biogás (BGS, 2019, on-line).

Para realizar esse adubo, é recomendado pela Sociedade Brasileira de Ciência do Solo - SBCS (2004, p. 225) que seja feita a técnica de coroamento. Essa técnica consiste em cavar uma vala ao redor da árvore, em forma de círculo, com certa profundidade, para que o adubo seja posto mais próximo das raízes da planta, sem causar danos à mesma. Essa coroa deve ser feita respeitando um limite de 20 a $30 \mathrm{~cm}$ do tronco.

Considerando as recomendações da SBCS (2004, p.225), a coroa deve ter profundidade de $15 \mathrm{~cm}$, largura de $10 \mathrm{~cm}$ e uma distância de $25 \mathrm{~cm}$ do tronco da árvore, conforme representado nas Figuras 1 e 2: 


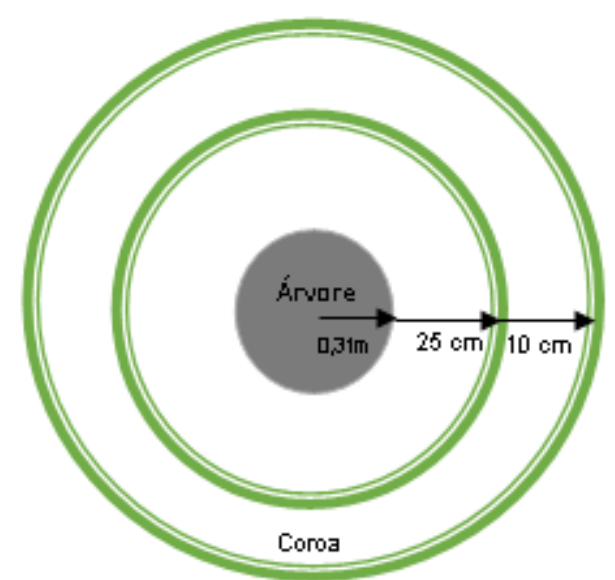

Figura 1: Largura da coroa e distância entre coroa e árvore

Fonte: Próprio Autor (2020)

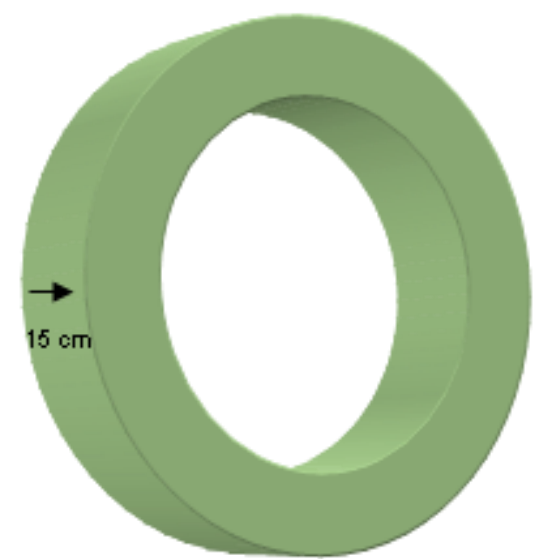

Figura 2: Profundidade da Coroa

Fonte: Próprio Autor (2020)

A partir disso, para calcular a quantidade de biofertilizante necessária, em $\mathrm{cm}^{3}$, para preencher o volume da coroa e adubar a árvore frutífera de maneira efetiva, é necessário, antes de tudo, conhecer a área da coroa. Para tanto, primeiramente foi calculada a área do círculo menor a partir do cálculo a seguir:

Transformação de medida do raio de metros para centímetros

$$
\begin{aligned}
& 1 \mathrm{~m}=100 \mathrm{~cm} \\
& 0,31 \mathrm{~m}=?
\end{aligned}
$$

Utilizando regra de três simples, obtêm-se

\section{Área do Círculo Menor}




$$
\begin{aligned}
\frac{1}{0,31}= & \frac{100}{A \overline{\overline{\mathrm{X}}}} \pi r^{2} \\
A & =3,14 *(31+25)^{2} \\
A & =3,14 * 56^{2} \\
A & =9.847,04 \mathrm{~cm}^{2}
\end{aligned}
$$

seguir:

Logo após, foi calculada a área do círculo maior como descrito a Área do Círculo Maior

$$
\begin{aligned}
& A=\pi r^{2} \\
& A=3,14 *(31+25+10)^{2} \\
& A=3,14 * 66^{2} \\
& A=3,14 * 4356 \\
& A=13.677,84 \mathrm{~cm}^{2}
\end{aligned}
$$

Com esses resultados em mãos, foi possível calcular a área da coroa através da diferença da área do círculo maior pelo menor:

Área da Coroa

$$
\begin{aligned}
& A_{\text {coroa }}=A_{\text {circulo maior }}-A_{\text {circulo menor }} \\
& A_{\text {coroa }}=13.677,84-9.847,04 \\
& A_{\text {coroa }}=3.830,8 \mathrm{~cm}^{2}
\end{aligned}
$$

Dessa forma, posteriormente, foi calculado o volume da coroa:

Volume da Coroa

$$
\begin{aligned}
& \mathrm{V}_{\text {coroa }}=\text { Área }{ }^{*} \text { Altura } \\
& \mathrm{V}_{\text {coroa }}=3.830,8^{*} 15 \\
& \mathrm{~V}_{\text {coroa }}=57.462 \mathrm{~cm}^{3}
\end{aligned}
$$

Seguindo a tabela do Sistema Internacional de Medidas, sabe-se que 1 $\mathrm{dm}^{3}$ equivale a $1.000 \mathrm{~cm}^{3}$. Assim, o biodigestor em sua capacidade máxima produzirá:

$$
\begin{aligned}
& \text { Volume biodigestor }=20,000 * 1.000 \\
& V_{\text {olume biodigestor }}=20.000 .000 \mathrm{~cm}^{3}
\end{aligned}
$$


Por fim, para saber quantas árvores frutíferas e, portanto, quantas coroas podem ser adubadas utilizando 0 biofertilizante produzido pelo biodigestor rural em sua capacidade máxima mensal, foi feito o seguinte cálculo:

$$
\begin{aligned}
& \text { Quantidade de Coroas }=\frac{V_{\text {biodigestor }}}{V_{\text {Coroa }}} \\
& Q_{\text {uantidade de Coroas }}=\frac{20.000 .000}{57.462}
\end{aligned}
$$

Quantidade de Coroas $=348$ coroas

Assim, é possível concluir que o agricultor em questão poderá adubar até 348 árvores frutíferas com o biofertilizante produzido pelo seu biodigestor rural, por mês.

Segundo os PCN's, o estudo de área e volume das figuras geométricas deve ser iniciado no Ensino Fundamental II, para que chegando ao Ensino Médio, esses alunos tenham condições de compreender demonstrações que resultem em fórmulas, como por exemplo, a área do círculo e, portanto, da coroa (BRASIL, 1998, p. 73-74).

\section{Força dos ventos e a produção de energia}

De acordo com dados coletados na empresa Energia Pura (Energia Pura, 2019, on-line), utilizando-se do equipamento para captação de ventos, é possível produzir $109 \mathrm{~kW}$ a partir de um vento de velocidade $6 \mathrm{~m} / \mathrm{s}$. Um residente da região semiárida brasileira decidiu instalar um equipamento para produzir energia eólica em sua casa.

Para tanto, ele precisava saber a média de ventos em sua localidade e consultando o Atlas do Potencial Eólico Brasileiro, encontrou um mapa da velocidade média anual do Nordeste (Figura 3), verificando que na sua região a mesma é de aproximadamente 6,5 m/s (AMARANTE et al., 2001, p. 26).

Utilizando as informações adquiridas a partir do Atlas do Potencial Eólico Brasileiro, da ANEEL e da Companhia de Eletricidade do Estado da Bahia COELBA, o residente utilizou a regra de três simples para descobrir quantos $\mathrm{kWh}$ seu equipamento produziria e quanto equivaleria à produção de $\mathrm{kWh}$ em desconto na conta de eletricidade (Tabela 2).

Tabela 2: Informações sobre a produção de energia elétrica em kWh a partir da velocidade média do vento

\begin{tabular}{cccc}
\hline $\begin{array}{c}\text { Vento velocidade } \\
\text { media }(\mathbf{m} / \mathbf{s})\end{array}$ & $\begin{array}{c}\text { Produção de } \\
\text { energia (kWh) }\end{array}$ & Preço do kWh & Custo mensal (R\$) \\
\hline- & - & 0,82115833 & 347,45 \\
6 & 109 & 0,82115833 & 89,51 \\
6,5 & $\mathbf{X}$ & 0,82115833 & $\mathbf{Y}$ \\
\hline
\end{tabular}

Fonte: Adaptado de COELBA (2019, on-line)

Revbea, São Paulo, v.16, № 1: 148-162, 2021. 
Regra de Três Simples

$$
\begin{array}{ll}
\frac{6}{6,5}=\frac{109}{x} & x=\frac{708,5}{6} \\
6 x=708,5 & x=118,08 \mathrm{kWh}
\end{array}
$$

\section{Regra de Três Simples}

$$
\begin{array}{ll}
\frac{1}{118,08}=\frac{0,82115833}{y} & Y=96,96 \\
Y=118,08 * 0,82115833 &
\end{array}
$$

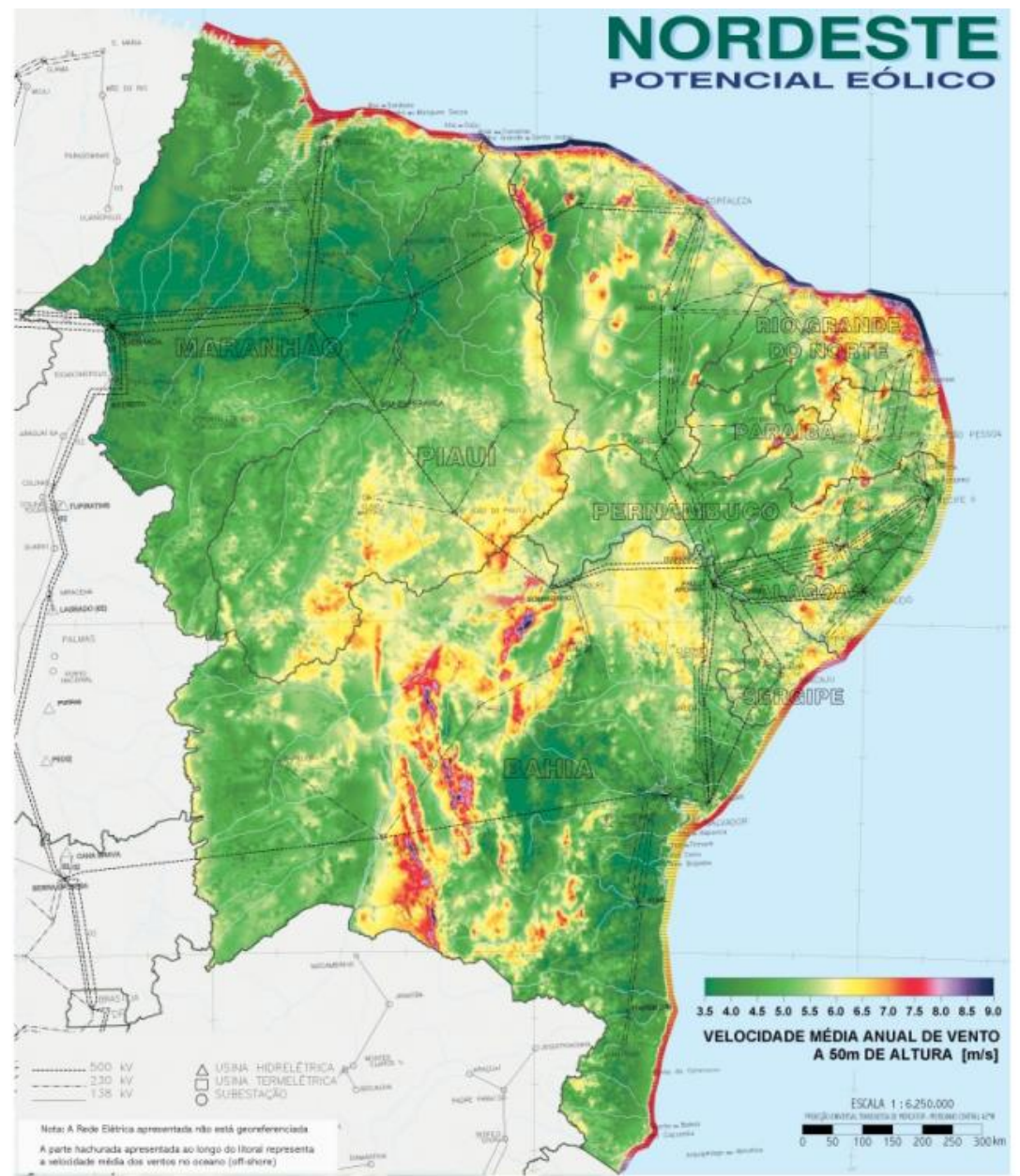

Figura 3: Velocidade média anual do vento na Região Nordeste.

Fonte: Atlas do potencial eólico brasileiro (AMARANTE et al., 2001, p. 26)

Dessa forma, é possível concluir que o morador em questão conseguirá economizar mensalmente $\mathrm{R} \$ 96,96$ em energia elétrica pela instalação do equipamento de produção de energia eólica. 
Segundo os PCN's, o letramento estatístico dos estudantes desde o início do Ensino Fundamental, incluindo noções de Média Aritmética é de grande importância. Acerca do conceito de velocidade média, deve ser abordado já no início do Ensino Médio. Já a equação de primeiro grau incompleta deve ser abordada a partir dos 6o e $7^{\circ}$ anos, para estimular 0 pensamento algébrico desde então (BRASIL, 1998, p. 81-82).

\section{Conclusões}

Partindo dos três modelos matemáticos construídos a partir de problemas ambientais de diferentes abordagens, foi possível abordar diversos conteúdos matemáticos, como regra de três simples, noções de geometria, média aritmética e velocidade média, por exemplo, além de conteúdos de outras disciplinas, como da botânica, de biologia e da cartografia, de geografia.

Isso mostra que é possível aplicar a modelagem matemática nos mais diversos assuntos, sobretudo no que diz respeito a temas ambientais. Essa percepção se alinha com a PNEA, que tem como um de seus objetivos a abordagem da Educação Ambiental em todos os níveis de ensino e em todas as disciplinas, a partir da interdisciplinaridade.

Além disso, a construção e exploração dessas sequências didáticas reforçaram o entendimento de que os conceitos e aplicações da Matemática estão presentes em várias situações do cotidiano, devendo, portanto, ser abordada de forma contextualizada para facilitar sua compreensão.

\section{Agradecimentos}

À Coordenação de Aperfeiçoamento de Pessoal de Nível Superior Brasil (CAPES) - Código de Financiamento 001. Ao Programa de PósGraduação em Ciência e Tecnologia Ambiental da Universidade de Pernambuco.

\section{Referências}

AMARANTE, O. A. et al. Atlas do potencial eólico brasileiro. In: Atlas do potencial eólico brasileiro. Ministério de Minas e Energia - Eletrobrás, 2001. 44p.

BARBOSA, G; LANGER, M. Uso de biodigestores em propriedades rurais: uma alternativa à sustentabilidade ambiental. Unoesc \& Ciência-ACSA, Joaçaba, v. 2, n. 1, p. 87-96, 2011.

BASSANEZI, R. C. Ensino-aprendizagem com Modelagem Matemática. 1 Ed. São Paulo: Contexto, 2002.

BGS. Equipamentos para biogás. Disponível em <https://www.bgsequipamentos.com.br> Acesso em: 20 de novembro de 2019. 
BIEMBENGUT, M. S.; HEIN, N. Modelagem Matemática no Ensino. São Paulo, Editora Contexto, 2005.

BRASIL. Agência Nacional De Energia Elétrica - ANEEL. Bandeira tarifária para mês de novembro é vermelha - patamar 1. Disponível em <https://www.aneel.gov.br> Acesso em: 06 de novembro de 2019.

BRASIL. Instituto Brasileiro de Geografia e Estatística - IBGE. Censo Agropecuário - Brasil, Grandes Regiões e Unidades da Federação, 2006. Disponível $<$ https://biblioteca.ibge.gov.br/visualizacao/periodicos/51/agro 2006.pdf > Acesso em: 04 de novembro de 2019.

BRASIL. Lei $n^{\circ}$ 9.795, de 27 de abril de 1999. Dispõe sobre a Educação Ambiental, institui a Política Nacional de Educação Ambiental e dá outras providências. D.O. de 28/04/1999, p.1. Disponível em: $<$ http://www.planalto.gov.br/ccivil 03/Leis/L9795.htm> Acesso em: 27 de outubro de 2019.

BRASIL. Secretaria de Educação Fundamental. Parâmetros curriculares nacionais : Matemática / Secretaria de Educação Fundamental. Brasília: MEC / SEF, 1998. $148 \mathrm{p}$.

CARDOSO, M. G. S. et al. Florescimento e frutificação de mangueira (Mangifera indica L.) Cv. Rosa promovidos por diferentes doses de paclobutrazol. Revista Brasileira de Fruticultura, v. 29, n. 2, p. 209-212, 2007.

Companhia de Eletricidade do Estado da Bahia - COELBA. Disponível em $<$ http://servicos.coelba.com.br/residencial-

rural/Pages/Baixa\%20Tens\%C3\%A3o/conheca-sua-conta.aspx> Acesso em: 06 de novembro de 2019.

DA SILVA, P. C. G. et al. Caracterização do Semiárido brasileiro: fatores naturais e humanos. Embrapa Semiárido-Capítulo em livro científico (ALICE), 2010.

DE OLIVEIRA FEITOSA, E. et al. Energia eólica como alternativa energética para convivência com semiárido no perímetro irrigado Tabuleiros de Russas. 2014.

DOS SANTOS, E. B.; DE NARDI JUNIOR, G. Produção de biogás a partir de rejeitos de origem animal. Tekhne e Logos, v. 4, n. 2, p. 80-90, 2013.

Energia Pura: Produtos Energia Eólica Disponível em: $<$ https://www.energiapura.com/portfolio posts/aerogerador-skystream-marine/> Acessado em: 20 de novembro de 2019

FAO - Food and Agriculture Organization of the United Nations. Food Wastage Footprint: Impacts on Natural Resources. 2013. Disponível em: $<$ http://www.fao.org/docrep/018/i3347e/i3347e.pdf>. Acesso em 04 de novembro de 2019. 
GALVAO, J.; BERMANN, C. Crise hídrica e energia: conflitos no uso múltiplo das águas. Estud. av., São Paulo, v. 29, n. 84, p. 43-68, Aug. 2015

MEDEIROS, M. C. S.; RIBEIRO, M. C. M.; FERREIRA, C. M. A. Meio Ambiente e Educação Ambiental nas Escolas Públicas. Âmbito Jurídico, 2011. Disponível em: < https://ambitojuridico.com.br/cadernos/direito-ambiental/meioambiente-e-educacao-ambiental-nas-escolas-publicas/>. Acesso em: 03 de março de 2020.

PACHECO, F. Energias Renováveis: breves conceitos. Conjuntura e Planejamento, v. 149, p. 4-11, 2006.

PINTO, L. I. C.; MARTINS, F. R.; PEREIRA, E. B. O mercado brasileiro da energia eólica, impactos sociais e ambientais. Ambiente \& Água-An Interdisciplinary Journal of Applied Science, v. 12, n. 6, p. 1082-1100, 2017.

SEGANFREDO, M. A. Os rejeitos de animais podem causar poluição também nos solos de baixa fertilidade e nos solos profundos, como aqueles da região dos Cerrados. Embrapa Suínos e Aves-Comunicado Técnico (INFOTECAE), 2002.

Sociedade Brasileira de Ciência do Solo - SBCS. Comissão de Química e Fertilidade do Solo. Manual de adubação e de calagem para os Estados do Rio Grande do Sul e de Santa Catarina - 10. ed. - Porto Alegre, 2004. 